\title{
Fracionamento dos carboidratos de silagens de milho safrinha colhidas em diferentes alturas de corte
}

\author{
Carbohydrates fractioning of late crop corn silages harvested at different cutting height
}

\author{
Luís Felipe Brancher Pedói* José Laerte NörnbergII João Pedro Velho ${ }^{\mathrm{I}}$ Fernanda Hentz ${ }^{\mathrm{II}}$ \\ João Dionísio Henn ${ }^{\mathrm{IV}}$ Júlio Otávio Jardim Barcellos ${ }^{\mathrm{V}}$ Ione Maria Pereira Haygert Velho $^{\mathrm{VI}}$ \\ Fábio Ritter Marx ${ }^{\mathrm{VII}}$
}

\section{RESUMO}

Este trabalho teve como objetivo verificar se há alteração na composição dos carboidratos de silagens de milho safrinha quando colhidas nas alturas de corte (AC) de 20, 45, 70 e $95 \mathrm{~cm}$ acima do solo. O experimento foi conduzido em delineamento completamente casualizado, com quatro unidades experimentais (minisilos) por tratamento. A matéria seca aumentou linearmente (MS $=27,25+0,06928 * A C$, onde: $R^{2}=0,82$ e $\left.P<0,01\right)$ com a elevação da AC pela maior proporção de grãos e menor proporção de colmo na massa ensilada. Os valores de fibra em detergente neutro corrigida para cinzas $e$ proteína (FDNcp) e lignina ( $L D A)$ diminuíram com a elevação na $A C, F D N c p=43,75-0,08411^{*} A C\left(R^{2}=0,47\right.$ e $\left.P<0,01\right)$ e $L D A=6,983-0,03156 * A C\left(R^{2}=0,49\right.$ e $\left.P<0,01\right)$, respectivamente. $O$ teor de carboidratos não-fibrosos $\left(C N F=41,57+0,07861^{*} A C\right.$, onde: $R^{2}=0,54$ e $\left.P<0,01\right)$ e a fração $B 1$ dos carboidratos $\left(B 1=27,16+0,1239 * A C\right.$, em que: $R^{2}=0,66$ e $\left.P<0,01\right)$ aumentaram com a elevação da AC. O cultivo de milho durante a época denominada safrinha na região Sul do Brasil proporciona a produção de silagem de alta qualidade por apresentar alto teor de amido e baixo de fibra em detergente neutro. A elevação na altura de corte das plantas de milho altera a distribuição dos carboidratos aumentando a proporção de amido e reduzindo o teor de fibras e lignina na silagem.

Palavras-chave: açúcares, amido, carboidratos não-fibrosos, carboidratos totais, fibra em detergente, lignina.

\begin{abstract}
The objective was to verify if there are changes in the carbohydrates composition of late crop corn silages harvested at 20,45, 70 and $95 \mathrm{~cm}$ of cutting height $(\mathrm{CH})$. The research was conducted in a randomized entirely design with four replications (mini-silos) per treatment. The dry matter content increased linearly $D M=27.25+0.06928 * C H\left(R^{2}=0.82\right.$ and $\mathrm{P}<0.01$ ) with the $\mathrm{CH}$ elevation due to the larger grain proportion in the ensiled mass. The neutral detergent fiber corrected for ashes and protein (NDFap) and lignin (ADL) values lowered with the $C H$ elevation, NDFap $=43.75-$ $0.08411^{*} \mathrm{CH} \quad\left(R^{2}=0.47\right.$ and $\left.P<0.01\right)$ and $A D L=6.983-$ $0.03156 * C H\left(R^{2}=0.49\right.$ and $\left.P<0.01\right)$, respectively. The carbohydrates $B 1=27.16+0.1239 * C H\left(R^{2}=0.66\right.$ and $P<0.01)$ fraction and the non-fiber carbohydrates $N F C=41.57+0.07861 * C H\left(R^{2}=0.54\right.$ and $\left.P<0.01\right)$ increased linearly with the $\mathrm{CH}$ elevation. The late corn cropping in the south region of Brazil lead to high quality silages, with high starch and low neutral detergent fiber values. The $\mathrm{CH}$ elevation in the corn plant changes the carbohydrates distribution, with higher starch and lower neutral detergent fiber and lignin values in the silage.
\end{abstract}

Key words: sugar, starch, non-fiber carbohydrate, total carbohydrate, detergent fiber, lignin.

\section{INTRODUÇÃO}

Na região Sul do Brasil, principalmente em Santa Catarina e no Rio Grande do Sul, nos últimos

IPrograma de Pós-graduação em Zootecnia, Universidade Federal do Rio Grande do Sul (UFRGS), Porto Alegre, RS, Brasil. E-mail: pedohzoot@hotmail.com.*Autor para correspondência.

IIDepartamento de Tecnologia e Ciência dos Alimentos, Universidade Federal de Santa Maria (UFSM), Santa Maria, RS, Brasil.

IIICurso de Zootecnia, Universidade Estadual de Santa Catarina (UDESC), Chapecó, SC, Brasil.

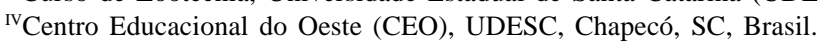

vepartamento de Zootecnia, UFRGS, Porto Alegre, RS, Brasil.

VIEscola Estadual Técnica Celeste Gobbato (EETCG), Palmeira das Missões, RS, Brasil.

${ }^{\mathrm{VII}}$ Curso de Zootecnia, UFSM, Santa Maria, RS, Brasil. 
anos, tem aumentado a produção de milho safrinha (MSaf) em função do incremento na produção de espécies vegetais colhidas em dezembro ou em meados de janeiro, o que viabiliza o cultivo de milho para grão ou ensilagem após este período.

Recentemente, também tem havido interesse no MSaf pela nova oportunidade de incremento de produção, sobretudo pelo aumento da demanda pelo grão de milho como commodity para a produção de etanol e o MSaf sendo, em parte, destinado à produção de silagem. Nesse sentido, aumenta o interesse do efeito da temperatura ambiental decrescente sobre o desenvolvimento dessa cultura, especialmente em relação à fração de carboidratos da planta e à qualidade fermentativa da silagem produzida (VELHO et al., 2007a).

Em revisão sobre o efeito da temperatura na produção de milho como forrageira, CRUZ \& PEREIRA FILHO (2001) citam vários autores, ressaltando que a temperatura requerida para o milho forrageiro é menor que para a produção de grãos porque ele é colhido antes da maturação do grão e pode ser produzido em regiões onde a temperatura média na estação de crescimento chega a $13,5^{\circ} \mathrm{C}$. Esses autores ainda mencionam que a baixa temperatura durante todo o ciclo, nas regiões frias da Europa e da América do Norte, torna a qualidade do colmo e das folhas tão boas quanto à da espiga. Esta afirmação não pode ser extrapolada para Santa Catarina e para o Rio Grande do Sul devido às elevadas temperaturas observadas nos meses de janeiro, fevereiro e março nesses Estados, mas permite afirmar que silagens de MSaf podem ter maior concentração energética que silagens produzidas na época normal.

A elevação na altura de corte (AC) da planta de milho visa incrementar o valor nutricional da silagem pelo aumento de frações mais digestíveis. Ela também serve para aumentar a reciclagem de matéria orgânica do solo, retornando grandes quantidades de potássio, pois a maior concentração desse elemento se encontra nos internódios inferiores da planta (NUSSIO et al., 2001).

Portanto, o objetivou deste trabalho foi verificar se há alteração na composição dos carboidratos de silagens de milho safrinha quando colhidas em diferentes alturas de corte.

\section{MATERIAL E MÉTODOS}

O trabalho de campo foi realizado em uma propriedade particular em Pinhalzinho, Santa Catarina, cuja sede do município está localizada a $515 \mathrm{~m}$ de altitude. O solo é classificado como Cambissolo háplico
(EMBRAPA, 1999). O clima é mesotérmico úmido com verões quentes e médias anuais de precipitação pluviométrica oscilando entre 1.500 e $2.000 \mathrm{~mm}$.

Foi utilizado um híbrido de ciclo precoce com grão semiduro, de cor alaranjada, semeado na primeira quinzena de janeiro de 2007, com espaçamento entre linhas de $0,75 \mathrm{~m}$. Não foi utilizada adubação de base, visto que parte dos produtores rurais da região Oeste de Santa Catarina cultivam MSaf nas glebas de terra, anteriormente ocupadas por fumo, a fim de aproveitar possível fertilidade residual desta cultura que é estabelecida com uma alta adubação com NPK, da ordem de $1.000 \mathrm{~kg} \mathrm{ha}^{-1}$. Todavia, os autores deste trabalho recomendam o uso de adubação própria para produção de silagem de planta inteira de milho, independente da época de cultivo ou do histórico da gleba de terra, evitando exaurir os nutrientes do solo.

As plantas de milho foram colhidas no final do mês de abril de 2007, seguindo os tratamentos que foram constituídos pelo corte a 20, 45, 70 e 95cm acima do solo. Imediatamente após o corte, as plantas foram picadas em ensiladeira estacionária, em partículas com tamanho teórico médio de dois centímetros e a seguir foram confeccionados quatro minisilos constituídos por três sacos plásticos sobrepostos. Para facilitar a compactação por pisoteio, os sacos foram armados em baldes com capacidade de 20L. Após o fechamento, os minisilos foram retirados dos baldes e armazenados em temperatura ambiente, abrigados da radiação solar. Após 78 dias da ensilagem, os minisilos foram abertos, sendo a camada superior de cada um destes desprezada e o restante do material homogeneizado.

Os valores de $\mathrm{pH}$ foram determinados com potenciômetro digital no suco das silagens, obtido por prensagem. Amatéria seca(MS), a matéria mineral (MM) e o extrato etéreo (EE) foram determinados conforme AOAC (1995). Já a fibra em detergente neutro corrigida para cinzas e proteína (FDNcp), a fibra em detergente ácido corrigida para cinzas e proteína (FDAcp), a hemicelulose, a celulose e a lignina em detergente ácido (LDA) foram determinadas conforme MERTENS (2002) e o nitrogênio insolúvel em detergente neutro (NIDN) e o nitrogênio insolúvel em detergente ácido (NIDA) foram determinados de acordo com LICITRA et al. (1996).

Os valores de ácidos orgânicos, proteína bruta do resíduo insolúvel em etanol (PBRIE), matéria orgânica do resíduo insolúvel em etanol (MORIE) e açúcares solúveis foram obtidos conforme descrito por HALL (2000). Para a quantificação do amido, foi realizada a determinação da fibra solúvel, conforme AOAC (1995), adequando-se o cálculo proposto por 
HALL (2000): $A M I D O=($ MORIE - PBRIE $)-($ MORIDN - PBRDIN) - Fibra Solúvel, em que: MORIDN = matéria orgânica do resíduo insolúvel em detergente neutro; PBRIDN = proteína bruta do resíduo insolúvel em detergente neutro.

O fracionamento dos carboidratos foi obtido conforme SNIFFEN et al. (1992), em que a fração “A” é representada pelos compostos solúveis de alta taxa de degradação, as frações "B" correspondem a compostos de degradação moderada e a fração " $C$ " é representada pelos compostos estruturais indegradáveis e indigestíveis.

O delineamento utilizado foi o inteiramente casualizado com quatro repetições (minisilos) por tratamento. Realizou-se estudo por regressão linear simples utilizando-se o pacote estatístico Minitab (MCKENZIE \& GOLDMAN, 1999).

\section{RESULTADOS E DISCUSSÃO}

Os teores de MS das silagens (Tabelas $1 \mathrm{e}$ 2) oriundas de plantas colhidas em diferentes AC aumentaram linearmente $(P<0,01)$, havendo uma variação de aproximadamente $20 \%$ entre AC mais baixa $(20 \mathrm{~cm})$ e a mais alta $(95 \mathrm{~cm})$. A amplitude do teor de MS (29 a 34\%) está dentro da faixa que proporciona o desenvolvimento de bactérias lácticas. Ressalta-se que a AC mais alta não prejudicou a fermentação em função da MS, visto que a colheita das plantas foi realizada em estádio vegetativo "precoce" para escapar de possíveis geadas que podem ocorrer nesta época do ano (abril) no Oeste Catarinense. Entretanto, deve-se ter cuidado com a elevação da AC quando as plantas estiverem em estádio de maturação mais avançado porque a mesma aumenta o teor de MS e os valores altos desta fração contribuem para diminuir a compactação na ensilagem.

Tabela 1 - Médias e erro padrão médio (EPM) das silagens de milho colhidas em diferentes alturas.

\begin{tabular}{|c|c|c|c|c|c|}
\hline \multirow{2}{*}{ Parâmetro } & \multicolumn{4}{|c|}{ 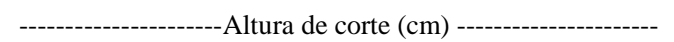 } & \multirow{2}{*}{ EPM } \\
\hline & 20 & 45 & 70 & 95 & \\
\hline Massa específica (kg de $\mathrm{MV} \mathrm{m}^{-3}$ ) & 701,2 & 701,2 & 710,0 & 707,5 & 5,42 \\
\hline Matéria seca (\%) & 28,6 & 30,8 & 31,3 & 34,2 & 0,55 \\
\hline Massa específica ( $\mathrm{kg}$ de $\mathrm{MS} \mathrm{m} \mathrm{m}^{-3}$ ) & 200,7 & 215,9 & 222,2 & 241,6 & 4,20 \\
\hline Matéria orgânica (\%) & 95,6 & 95,9 & 96,2 & 95,8 & 0,11 \\
\hline Extrato etéreo (\% MS) & 2,2 & 2,5 & 2,5 & 2,8 & 0,09 \\
\hline $\mathrm{pH}$ & 3,71 & 3,72 & 3,70 & 3,74 & 0,01 \\
\hline Carboidratos totais (\% MS) & 81,8 & 81,1 & 81,7 & 81,4 & 0,34 \\
\hline Carboidratos não-fibrosos (\% MS) & 43,6 & 43,6 & 48,7 & 48,4 & 0,77 \\
\hline Ácidos orgânicos (\% MS) & 11,7 & 9,6 & 9,2 & 9,1 & 0,44 \\
\hline Açúcares solúveis (\% MS) & 0,19 & 0,18 & 0,42 & 0,41 & 0,06 \\
\hline MORIE (\% MS) & 76,7 & 78,1 & 78,8 & 78,7 & 0,51 \\
\hline Fibra solúvel (\% MS) & 1,7 & 2,2 & 2,2 & 0,3 & 0,24 \\
\hline PBRIE (\% MS) & 2,9 & 3,3 & 3,5 & 3,3 & 0,06 \\
\hline Amido (\% MS) & 30,0 & 31,6 & 36,9 & 38,6 & 1,10 \\
\hline Fibra em detergente neutro (\% MS) & 44,7 & 43,7 & 39,1 & 39,4 & 0,81 \\
\hline FDNcp (\% MS) & 42,0 & 41,0 & 36,2 & 36,6 & 0,88 \\
\hline Fibra em detergente ácido (\% MS) & 28,7 & 26,6 & 24,9 & 23,6 & 0,67 \\
\hline FDAcp (\% MS) & 25,4 & 19,1 & 17,4 & 14,7 & 1,29 \\
\hline Hemicelulose & 17,2 & 22,4 & 19,4 & 22,6 & 1,18 \\
\hline Celulose & 20,4 & 19,5 & 17,8 & 18,5 & 0,47 \\
\hline Lignina & 6,5 & 5,3 & 4,9 & 4,0 & 0,32 \\
\hline Fracão A (\% CT) & $\begin{array}{c}\text { carboid } \\
20,9\end{array}$ & $\begin{array}{c}\text { ado SN } \\
20,0\end{array}$ & $\begin{array}{c}\text { al. (199. } \\
20,5\end{array}$ & 18,4 & 0,45 \\
\hline Fração B1 (\% CT) & 30,0 & 31,6 & 36,9 & 38,6 & 1,10 \\
\hline Fração B2 (\% CT) & 30,8 & 30,4 & 28,7 & 31,7 & 1,15 \\
\hline Fração C (\% CT) & 18,2 & 15,0 & 13,9 & 11,3 & 0,93 \\
\hline
\end{tabular}

MORIE = Matéria orgânica do resíduo insolúvel em etanol; PBRIE = Proteína bruta do resíduo insolúvel em etanol; FDNcp = Fibra em detergente neutro corrigida para cinzas e proteína; FDAcp = Fibra em detergente ácido corrigida para cinzas e proteína.

Ciência Rural, v.39, n.1, jan-fev, 2009. 
Tabela 2 - Regressões, probabilidades das regressões lineares e quadráticas e coeficiente de determinação $\left(\mathrm{r}^{2}\right)$ para as silagens de milho colhidas em diferentes alturas.

\begin{tabular}{|c|c|c|}
\hline Parâmetro & Regressão e probabilidade & $\mathrm{R}^{2}$ \\
\hline 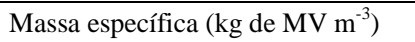 & $\mathrm{Y}=698,7(\mathrm{P}=0,588)$ & 0,021 \\
\hline Matéria seca (\%) & $\mathrm{Y}=27,25+0,06928 * \mathrm{AC}(\mathrm{P}=0,001)$ & 0,816 \\
\hline Massa específica ( $\mathrm{kg}$ de $\mathrm{MS} \mathrm{m} \mathrm{m}^{-3}$ ) & $\mathrm{Y}=190,4+0,5166 * \mathrm{AC}(\mathrm{P}=0,001)$ & 0,789 \\
\hline Matéria orgânica (\%) & $\mathrm{Y}=95,7(\mathrm{P}=0,394)$ & 0,052 \\
\hline Extrato etéreo (\% MS) & $\mathrm{Y}=2,059+0,00752 * \mathrm{AC}(\mathrm{P}=0,01)$ & 0,390 \\
\hline $\mathrm{pH}$ & $\mathrm{Y}=3,696(\mathrm{P}=0,507)$ & 0,032 \\
\hline Carboidratos totais (\% MS) & $\mathrm{Y}=81,64(\mathrm{P}=0,854)$ & 0,003 \\
\hline Carboidratos não-fibrosos (\% MS) & $\mathrm{Y}=41,57+0,07861 * \mathrm{AC}(\mathrm{P}=0,001)$ & 0,540 \\
\hline \multicolumn{3}{|c|}{ 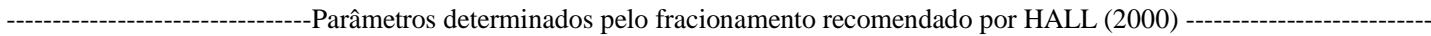 } \\
\hline Açúcares solúveis (\% MS) & $\mathrm{Y}=0,0989(\mathrm{P}=0,088)$ & 0,193 \\
\hline MORIE (\% MS) & $\mathrm{Y}=76,51+0,02745 * \mathrm{AC}(\mathrm{P}=0,135)$ & 0,152 \\
\hline Fibra solúvel (\% MS) & $\mathrm{Y}=0,1284+0,09423 * \mathrm{AC}(\mathrm{P}=0,048)-0,000965 \mathrm{AC}^{2}(\mathrm{P}=0,001)$ & 0,669 \\
\hline PBRIE (\% MS) & $\mathrm{Y}=2,445+0,03080 * \mathrm{AC}(\mathrm{P}=0,034)-0,000228 \mathrm{AC}^{2}(\mathrm{P}=0,004)$ & 0,634 \\
\hline Amido (\% MS) & $\mathrm{Y}=27,16+0,1239 * \mathrm{AC}(\mathrm{P}=0,001)$ & 0,658 \\
\hline \multicolumn{3}{|c|}{ 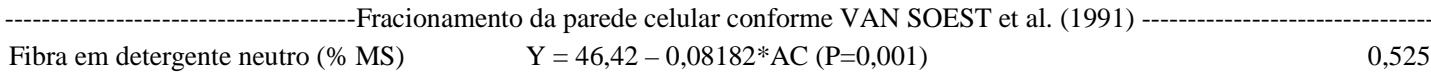 } \\
\hline FDNcp (\% MS) & $\mathrm{Y}=43,75-0,08411 * \mathrm{AC}(\mathrm{P}=0,003)$ & 0,468 \\
\hline Fibra em detergente ácido (\% MS) & $\mathrm{Y}=29,83-0,06795 * \mathrm{AC}(\mathrm{P}=0,001)$ & 0,532 \\
\hline FDAcp (\% MS) & $\mathrm{Y}=26,92-0,1351 * \mathrm{AC}(\mathrm{P}=0,001)$ & 0,568 \\
\hline Hemicelulose & $\mathrm{Y}=17,35+0,05268 * \mathrm{AC}(\mathrm{P}=0,222)$ & 0,104 \\
\hline Celulose & $\mathrm{Y}=20,79(\mathrm{P}=0,069)$ & 0,217 \\
\hline Lignina & $\mathrm{Y}=6,983-0,03156 * \mathrm{AC}(\mathrm{P}=0,003)$ & 0,490 \\
\hline Fração A (\% CT) & $\begin{array}{l}\text { ento dos carboidratos segundo SNIFFEN et al. (1992) } \\
\mathrm{Y}=21,57(\mathrm{P}=0,077)\end{array}$ & 0,206 \\
\hline Fração B1 (\% CT) & $\mathrm{Y}=27,16+0,1239 * \mathrm{AC}(\mathrm{P}=0,001)$ & 0,658 \\
\hline Fração B2 (\% CT) & $\mathrm{Y}=31,63-0,00815 * \mathrm{AC}(\mathrm{P}=0,851)$ & 0,003 \\
\hline Fração C (\% CT) & $\mathrm{Y}=19,65-0,08766 * \mathrm{AC}(\mathrm{P}=0,004)$ & 0,467 \\
\hline
\end{tabular}

AC = Altura de corte das plantas de milho no momento da colheita; MORIE = Matéria orgânica do resíduo insolúvel em etanol; PBRIE = Proteína bruta do resíduo insolúvel em etanol; FDNcp = Fibra em detergente neutro corrigida para cinzas e proteína; FDAcp = Fibra em detergente ácido corrigida para cinzas e proteína.

As diferenças observadas na MS das silagens devemse principalmente às variações de colmo absolutas.

Neste trabalho, as massas específicas não seguiram a tendência que geralmente ocorre em silos do tipo trincheira ou de superfície em que o incremento na MS ocasiona decréscimo na compactação porque foi colocado o mesmo volume de silagem por unidade de área, simulando a maximização de uso do silo, visto que os produtores rurais enchem os silos trincheira a partir da altura desses silos. Assim, a massa específica aumentou conforme o aumento da MS.

Ao avaliar silagens de milho resultantes do arranjo fatorial dois tamanhos de partícula (pequena 0,2 a $0,6 \mathrm{~cm}$; grande 1,0 a $2,0 \mathrm{~cm}$ ), duas alturas de corte $(15$ e $39 \mathrm{~cm})$ e dois tipos de silos (semitrincheira e laboratorial de PVC), NEUMANN et al. (2007) verificaram diferença $(\mathrm{P}<0,05)$ na compactação das silagens quanto ao tamanho de partícula e ao tipo de silo, de forma que houve maior densidade nos silos laboratoriais dadas as condições controladas. Estes autores comentam que silos laboratoriais não permitem que sejam mensurados os parâmetros na mesma magnitude que nos silos convencionais (trincheira ou de superfície), porém, eles permitem a comparação simultânea de diversos tratamentos.

Todas as massas específicas (Tabela 1) foram adequadas para a preservação das silagens e superiores para as compactações máximas de 195; 174; 170 e $182 \mathrm{~kg}$ de $\mathrm{MS} \mathrm{m}^{-3}$ obtidas, respectivamente, por JOHNSON et al. (2002), SENGER et al. (2005), VELHO et al. (2007b) e NEUMANN et al. (2007), que também trabalharam com minisilos. Os fatores que afetam a densidade de compactação são: peso do trator, tempo de compactação, teor de água das plantas, altura do 
silo e tamanho das partículas (MUCK \& HOLMES, 2000). Ressalta-se que a AC das plantas de milho pode alterar o teor de MS, influenciando a compactação, como já mencionado pelos últimos autores citados.

Os valores de $\mathrm{pH}$ (Tabela 1 ) são apropriados às silagens de milho, cujo parâmetro permite conjeturar que, sob este aspecto, a fermentação foi adequada em todos os tratamentos. $\mathrm{O}$ baixo $\mathrm{R}^{2}=0,03$ da equação é porque o $\mathrm{pH}$ não variou $(\mathrm{P}=0,51)$ em função das $\mathrm{AC}$.

Houve diferença $(\mathrm{P}<0,01)$ para o teor de extrato etéreo das silagens com a AC (Tabela 2). Esta análise não é a mais recomendada para determinar a fração lipídica que realmente contribui para o metabolismo animal, uma vez que compostos nãoenergéticos, tais como pigmentos, são carreados pelo éter juntamente com a gordura, aumentando o teor de extrato etéreo. Possivelmente as diferenças estatísticas observadas devem-se ao incremento das proporções de folhas e grãos nas alturas mais elevadas, cujos componentes apresentam maiores quantidades de pigmentos, ceras e triglicerídeos.

Não houve diferença $(\mathrm{P}=0,85)$ para carboidratos totais (CT) nas alturas avaliadas (Tabela 1 e 2), cujos teores médios estão próximos à maioria dos valores reportados pela literatura, visto que em silagens de milho as proporções de matéria mineral, PB e EE são relativamente constantes. Na segunda edição das Tabelas Brasileiras de Composição de Alimentos para Bovinos, VALADARES FILHO et al. (2006) reportam valor médio de $84,8 \%$ de CT referente a 96 amostras de silagem de milho com desvio padrão de 2,1. Logo, este parâmetro não é o mais adequado para avaliar alterações nos carboidratos, sendo necessário fracioná-los. Os carboidratos não-fibrosos (CNF) aumentaram em função da AC (Tabelas 1 e 2). Esta fração é representada por mono e dissacarídeos, amido e fibra solúvel. VALADARES FILHO et al. (2006) relatam o valor de 34,4\% de CNF para 29 silagens de milho com desvio padrão de 2,3 .

Houve efeito $(\mathrm{P}<0,04)$ para os ácidos orgânicos (Tabelas 1 e 2) em função das AC. A silagem de processo fermentativo adequado apresenta 6 a 8\% da MS em ácido láctico, menos que 2\% da MS em ácido acético, de 0 a 1\% da MS de ácido propiônico e menos de 0,1\% da MS em ácido butírico (FERREIRA, 2001). Considerando os valores máximos da amplitude mencionada pelo autor supracitado, há um total de $11,1 \%$ da MS, cujo valor é próximo aos verificados neste experimento.

Não houve diferença $(\mathrm{P}=0,09)$ quanto aos açúcares solúveis das silagens. Os valores obtidos são extremamente baixos, indicando que estes foram praticamente exauridos pelos microorganismos presentes na fermentação, o que é desejável para a adequada conservação da forragem. A fração MORIE não sofreu efeito da $\mathrm{AC}(\mathrm{P}=0,13)$, cujos valores são condizentes com os dados apresentados por HALL (2000) e VELHO et al. (2006), o que ao mesmo tempo permite conjecturar que a mesma está distribuída de maneira uniforme ao longo de toda a planta de milho.

A FS abrange as pectinas, as ß-glucanas e as frutanas, que são de fermentação moderada, mas $100 \%$ degradáveis e fornecem energia aos microrganismos ruminais com certa facilidade. Para silagens de milho, HALL (2000) apresenta valores médios de FS da ordem de 5\% da matéria seca, valores mais altos que os encontrados no presente trabalho (Tabela 1). A FS apresentou efeito quadrático (Tabela 2), atingindo ponto de máxima aos $48,8 \mathrm{~cm}$ de AC (2,4\% da MS). Provavelmente, o baixo teor de FS no corte de $95 \mathrm{~cm}$ seja decorrente da maior participação de folhas mais jovens. Ressalta-se que para alimentos energéticos como silagem de milho quanto menos fibra (independente da forma) melhor. A PBRIE, constituída por peptídeos, proteína verdadeira e proteína ligada à parede celular, insolúveis em etanol 80\%, apresentou efeito quadrático (Tabela 2).

$\mathrm{O}$ amido apresentou acréscimo linear de acordo com a AC das plantas de milho (Tabelas 1 e 2), sendo o incremento bastante expressivo, uma vez que o teor inicial (20 cm) já era alto (30,0\% da MS) quando comparado ao valor médio de amido em silagens de milho (25,6\% na MS) apontado por VALADARES FILHO et al. (2006), referente a 11 amostras. Ambos os trabalhos citam valores altos de amido, porém os mesmos não podem ser empregados como média nacional e/ou regional porque apenas trabalhos mais recentes determinaram esta fração, ou seja, há deficiência na avaliação de alimentos amiláceos, sobretudo aqueles destinados à nutrição de ruminantes.

Os parâmetros FDN, FDNcp, FDA, FDAcp

e lignina (Tabela 1) apresentaram efeito linear decrescente $(\mathrm{P}<0,01)$ em relação ao aumento na AC das plantas de milho. Considerando-se as Tabelas Brasileiras de Composição de Alimentos para Bovinos, publicadas por VALADARES FILHO et al. (2006), como referência nacional, uma vez que reúne dados de todas as regiões do país, fica evidente a excelente qualidade das silagens de milho geradas neste experimento, com valores baixos de FDN e menores ainda quando corrigidos para cinzas e proteína. Estes autores relatam valores de FDN, FDNp (corrigida para proteína) e de FDNcp, respectivamente, da ordem de 55,4\% da MS (247 amostras), 52,4\% da MS (seis amostras) e 51,8\% da MS (21 amostras). Portanto, mesmo a silagem colhida a $20 \mathrm{~cm}$, que apresentou maior teor de FDN, contém 9,8 
unidades percentuais a menos que a reportada por VALADARES FILHO (2006): 51,8\% da MS. Ao estudar a manipulação da AC da planta de milho para ensilagem, RESTLE et al. (2002) observaram FDN, não-corrigida para cinzas e proteína, de $41,5 \%$ da MS (corte a $42 \mathrm{~cm}$ de altura), valores próximos aos encontrados no presente trabalho. Os valores de FDNcp deste trabalho e os de RESTLE et al. (2002) demonstram que é possível incrementar consideravelmente o valor nutricional das silagens brasileiras.

A silagem de milho é um dos poucos alimentos considerados como volumoso e concentrado simultaneamente. Em função do alto teor de amido e do baixo de FDNcp como aqui obtidos, há menor necessidade de concentrado na dieta, o que repercute na economicidade dos sistemas de produção. Provavelmente, estes resultados são oriundos da alta fertilidade do solo e das temperaturas mais amenas, que estimulam em menor proporção a deposição de parede celular.

As diferenças entre FDA e FDAcp foram de 3,$3 ; 7,5 ; 7,5$ e 8,9 unidades percentuais para os tratamentos 20, 45, 70 e 95cm acima do solo. Em geral, esta correção não é realizada na pressuposição de que o baixo pH da solução em detergente ácido é capaz de solubilizar os minerais. No entanto, isso não foi verificado neste estudo. Desse modo, sugere-se que a FDA, assim como vem sendo recomendado para a FDN, seja corrigida para cinzas e proteína.

A lignina é um dos principais fatores que limita a degradabilidade da parede celular (VAN SOEST, 1994), refletindo-se em maior tempo para esvaziamento do rúmen, que repercute em menor consumo. Para LDA, os valores encontrados são elevados, quando comparados com silagens de milho "normal” (32 a 38\% de MS) pelo NRC (2001), que apresenta valores médios de 2,6\% na MS, mas com o incremento da AC de 20 para $95 \mathrm{~cm}$ foi possível uma redução de 38,5\%.

A fração A, considerada total e prontamente degradada no rúmen, não diferiu entre as $\mathrm{AC}(\mathrm{P}=0,08)$, indicando que a quantidade de açúcares solúveis não sofreu alteração com a AC das plantas de MSaf. Na fração B1, que em silagens de milho é composta principalmente de amido, houve efeito linear crescente com a elevação da AC, justificado pela maior participação relativa de grãos. Tais valores encontramse próximos dos maiores valores (30\% de amido na MS) reportados por HALL (2000) e acima dos apresentados por VALADARES FILHO et al. (2006) (25,6\% de amido na MS) para silagens de milho produzidas e analisadas em experimentos nacionais.

A fração B2 dos carboidratos, a qual apresenta taxa de degradação variável, porém mais lenta que a $\mathrm{B} 1$, não diferiu entre os tratamentos $(\mathrm{P}=0,85)$. Entretanto, os valores observados estão abaixo dos $50,7 \%$ e $52,2 \%$ encontrados por CABRAL et al. (2000) e VELHO et al. (2007b), respectivamente, refletindo os baixos teores desta fração nas silagens do presente experimento.

A fração C, que representa a porção nãodegradável e indigestível dos carboidratos, mostrou diferença significativa $(\mathrm{P}<0,01)$ entre os tratamentos, sendo inferiores com o corte das plantas de milho realizado a $95 \mathrm{~cm}$ do solo, o que já era esperado pela menor participação de colmos onde se concentra a maior parte da LDA.

Os dados deste trabalho não podem ser transportados, nas mesmas proporções para um silo trincheira ou de superfície, porque foram gerados com minisilos experimentais, em condições controladas. No entanto, os dados demonstram que a silagem de planta inteira de MSaf pode gerar silagem de alto valor energético. Por isso, são necessários outros estudos que investiguem o potencial de produção (leite e carne) desta silagem, em especial nas condições de clima subtropical ou temperado, e as implicações do fotoperíodo negativo e da maior amplitude térmica diária da região Sul do país no material a ser ensilado e no produto após a fermentação.

Atualmente, no Brasil, há comercialização de automotrizes colhedoras de forragem para silagem que possibilitam maiores variações no ajuste da altura da plataforma de colheita, mas mesmo com os modelos tracionados é possível aumentar a AC a fim de facilitar a fermentação dos carboidratos da silagem pelos microorganismos ruminais pela maior quantidade de amido e pelo menor teor de FDN.

\section{CONCLUSÕES}

O cultivo de milho durante a época denominada safrinha na região Sul do Brasil gera silagem de alta qualidade por apresentar alto teor de amido e baixo de fibra em detergente neutro. A elevação na altura de corte das plantas aumenta o teor de matéria seca e altera a distribuição dos carboidratos, com incremento de carboidratos não-fibrosos e redução de fibra em detergente neutro, fibra em detergente ácido e lignina.

\section{AGRADECIMENTOS}

À Prefeitura Municipal de Pinhalzinho, Santa Catarina, e à Cooperativa Regional Itaipu (COOPERITAIPU), pelos recursos disponibilizados para realização do experimento. Ao Conselho Nacional de Desenvolvimento Científico e Tecnológico (CNPq), pela concessão da bolsa de mestrado a 
Luís Felipe Brancher Pedó, de doutorado a João Pedro Velho e de Produtividade em Pesquisa a Júlio Otávio Jardim Barcellos. À Fundação de Amparo à Pesquisa do Estado do Rio Grande do Sul (FAPERGS), pela bolsa de iniciação científica concedida a Fábio Ritter Marx.

\section{REFERÊNCIAS}

ASSOCIATION OF OFFICIAL ANALITICAL CHEMISTRY AOAC. Official methods of analysis. 16ed. Arlington: AOAC International, 1995. 1025p.

CABRAL, L.S. et al. Frações de carboidratos de alimentos volumosos e suas taxas de degradação estimadas pela técnica de produção de gases. Revista Brasileira de Zootecnia, v.29, n.6, p.2087-2098, 2000. (Supl.1).

CRUZ, J.C.; PEREIRA FILHO, I.A. Cultivares de milho para silagem. In: CRUZ, J.C. et al. (Eds.). Produção e utilização de silagem de milho e sorgo. Sete Lagoas: Embrapa Milho e Sorgo, 2001. p.11-37.

EMBRAPA. Centro Nacional de Pesquisa de Solos. Sistema Brasileiro de Classificação de Solos, 1999. Acesso em: 12 set. 2007. On line. Disponível em: <http://mapas.ibge.gov.br/ solos/viewer.htm>

FERREIRA, J.J. Estágio de maturação ideal para ensilagem do milho e do sorgo. In: CRUZ, J.C. et al. (Eds.). Produção e utilização de silagem de milho e sorgo. Sete Lagoas: Embrapa Milho e Sorgo, 2001. p.405-428.

HALL, M.B. Neutral detergent-soluble carbohydrates, nutritional relevance and analysis. A laboratory manual. Florida: University of Florida, 2000. 42p. (Bulletin 339).

JOHNSON, L.M. et al. Corn silage management: Effects of maturity, inoculation, and mechanical processing on pack density and aerobic stability. Journal of Dairy Science, v.85, n.2, p.434-444, 2002.

LICITRA, G. et al. Standardization of procedures for nitrogen fractionation of ruminants feeds. Animal Feed Science and Tecnhology, v.57, n.4, p.347-358, 1996.

MCKENZIE, J.; GOLDMAN, R.N. The student edition of Minitab for windows manual: release 12 . Belmont: Addison-Wesley Longman, Incorporated: Softcover ed, 1999. 592p.

MERTENS, D.R. Gravimetric determination of amylase-treated neutral detergent fiber in feeds with refluxing in beakers or crucibles: collaborative study. Journal of AOAC International, v.85, n.6, p.1211-1240, 2002.
MUCK, R.E.; HOLMES, B.J. Factors affecting bunker silo densities. Applied Engineering in Agriculture, v.16, p.613619, 2000.

NATIONAL RESEARCH COUNCIL (NRC). Nutrient requirements of dairy cattle. 7.rev ed. Washington D.C.: National Academy, 2001. 360p.

NEUMANN, M. et al. Características da fermentação da silagem obtida em diferentes tipos de silo sob efeito do tamanho de partícula e da altura de colheita das plantas de milho. Ciência Rural, v.37, n.3, p.847-854, 2007.

NUSSIO, L.G. et al. Importância da qualidade da porção vegetativa no valor alimentício da silagem de milho. In: SIMPÓSIO SOBRE PRODUÇÃO E UTILIZAÇÃO DE FORRAGENS CONSERVADAS, 2001, Maringá. Anais... Maringá: UEM/CCA/DZO, 2001. p.127-145.

RESTLE, J. et al. Manipulação da altura de corte da planta de milho (Zea mays, L.) para ensilagem visando a produção do novilho superprecoce. Revista Brasileira de Zootecnia, v.31, n.3, p.1235-1244, 2002.

SENGER, C.C.D. et al. Composição química e digestibilidade in vitro de silagens de milho com distintos teores de umidade e níveis de compactação. Ciência Rural, v.35, n.6, p.13931399, 2005.

SNIFFEN, C.J. et al. A net carbohydrate and protein system for evaluating cattle diets: carbohydrate and protein availability. Journal of Animal Science, v.70, p.3562-3577, 1992.

VALADARES FILHO, S.C. et al. Tabelas brasileiras de composição de alimentos para bovinos. Viçosa, MG: UFV, 2006. 329p.

VELHO, J.P. et al. Alterações bromatológicas nas frações dos carboidratos de silagens de milho "safrinha" sob diferentes tempos de exposição ao ar antes da ensilagem. Revista Brasileira de Zootecnia, v.35, n.4, p.1621-1628, 2006. (Supl.)

VELHO, J.P. et al. Potencial de produção de leite estimado pela planilha Milk 2006 de silagens de milho safrinha sob diferentes tempos de exposição ao ar antes da ensilagem. In: SEMINÁRIO NACIONAL MILHO SAFRINHA RUMO À ESTABILIDADE, 9., 2007, Dourados, MS. Anais... Dourados: EMBRAPA Agropecuária Oeste, 2007a. 483p. 427-431p.

VELHO, J.P. et al. Composição bromatológica de silagens de milho produzidas com diferentes densidades de compactação. Revista Brasileira de Zootecnia, v.36, n.5, p.1532-1538, 2007b. 